\title{
Pre-operative glucose as a screening tool in patients without diabetes
}

\section{Citation}

Wang, Rui. 2015. Pre-operative glucose as a screening tool in patients without diabetes. Doctoral dissertation, Harvard Medical School.

\section{Permanent link}

http://nrs.harvard.edu/urn-3:HUL.InstRepos:17295868

\section{Terms of Use}

This article was downloaded from Harvard University's DASH repository, and is made available under the terms and conditions applicable to Other Posted Material, as set forth at http:// nrs.harvard.edu/urn-3:HUL.InstRepos:dash.current.terms-of-use\#LAA

\section{Share Your Story}

The Harvard community has made this article openly available.

Please share how this access benefits you. Submit a story.

\section{Accessibility}




\begin{abstract}
Background: Although hyperglycemia has been associated with poor post-operative outcomes, pre-operative hyperglycemia is not used as a screening tool in patients without diabetes. We evaluated pre-operative glucose as a marker for post-operative outcomes in patients without diabetes in order to assess its usefulness as a potential screening tool.
\end{abstract}

Materials and methods: Clinical characteristics for a sample of 6,683 patients without diabetes who underwent non-emergent vascular and general surgery were collected from the American College of Surgeons National Surgical Quality Improvement Program, Brigham and Women's Hospital database. Last glucose measured within 30 days prior to surgery was the main predictor variable with post-operative infection within 30 days as the primary outcome.

Results: For patients without known diabetes with pre-operative glucose of 100-139 mg/dL and 140-179 mg/dL, post-operative infection rates were significantly higher $(9.33 \%$ and $10.16 \%$, respectively) than that of patients with pre-operative glucose of $70-99 \mathrm{mg} / \mathrm{dL}(5.62 \%, \mathrm{P}<0.001)$. The risk-adjusted odds of post-operative infection increased by $40 \%$ (95\% CI, 13\%-72\%) for each $40 \mathrm{mg} / \mathrm{dL}$ increase in pre-operative glucose over the range 70-179 mg/dL. Follow-up data demonstrated that $15 \%$ of patients with pre-operative glucose $\geq 100 \mathrm{mg} / \mathrm{dL}$ were diagnosed with diabetes within one year after surgery.

Conclusions: In patients without known diabetes, pre-operative glucose is a significant marker for post-operative complications even at moderate levels of hyperglycemia. Some of these patients likely had pre-diabetes or unrecognized diabetes at the time of surgery. Future studies are needed to determine whether such screening and follow-up of pre-operative hyperglycemia in all patients would be effective in lowering complication rates. 


\section{INTRODUCTION}

Hyperglycemia in patients without known diabetes has been associated with poor clinical outcomes. ${ }^{1-3}$ Reduced morbidity and mortality from improved glycemic control in surgical patients also support the association between hyperglycemia and post-operative outcomes. ${ }^{4-9}$ However, the risks of unrecognized hyperglycemia (in patients not known to have diabetes) prior to surgical operations remain unclear. Although Ramos et al. have investigated associations between post-operative hyperglycemia and post-operative complications, ${ }^{10}$ we were interested in using pre-operative blood glucose as a marker for post-operative complications in patients not known to have diabetes. These patients would not be expected to have HbA1c levels, making blood glucose screening a potentially useful tool to screen for post-operative risks and act as a gateway to connect these patients to short- and long-term monitoring and management of hyperglycemia.

Unrecognized pre-operative hyperglycemia is due to either undiagnosed diabetes, physiologic stress, or a combination, and may be a marker of poor outcomes or a primary pathologic process. ${ }^{4,10-12}$ Possible mechanisms linking hyperglycemia with worse outcomes (besides an undiagnosed illness causing physiologic stress) include derangements in leukocyte function, glycosylation and inactivation of immunoglobulins (leading to immune dysfunction), and collagen glycosylation (leading to poor healing from wounds and organ damage). ${ }^{13-16}$ However, since there are likely many confounding factors contributing to the relationship between pre-operative hyperglycemia and post-operative complications, we sought to assess preoperative glucose as a marker, not as a causal determinant, of post-operative complications.

There have been a few studies investigating the link between pre-operative glucose levels and post-operative outcomes but the results have been mixed. Pre-operative hyperglycemia was 
shown to be associated with increased hospital mortality in diabetic and non-diabetic patients. ${ }^{11,17}$ However, a study of surgical patients with aneurysmal subarachnoid hemorrhage showed that admission hyperglycemia was not associated with worse outcomes. ${ }^{18}$

Our study assesses pre-operative glucose as a marker for post-operative complications in a cohort of patients without known diabetes admitted for non-emergent non-cardiac surgery, which represents a unique chance to evaluate pre-operative screening for hyperglycemia in patients with lower levels of physiologic stress than previous study populations. Randomly tested glucose levels have been shown to be efficient in identifying pre-diabetic and undiagnosed diabetic patients. ${ }^{19}$ Moreover, once screened and identified, these patients represent a population for whom perioperative management of hyperglycemia could be initiated in an attempt to improve outcomes. We also examined the incidence of diagnosed diabetes in our study cohort at one year follow-up.

\section{METHODS}

\section{Study cohort}

The initial sample from the American College of Surgeons National Surgical Quality Improvement Program, Brigham and Women's Hospital (ACS NSQIP BWH) database contained 10,812 randomly selected patients who underwent non-emergent vascular and general surgery at BWH from 1/1/2005 to 4/5/2010. We excluded patients who had known diagnosis of diabetes or pre-operative sepsis. ACS NSQIP-defined variables such as demographics, surgical profile, preoperative risk factors, pre-operative laboratory values, American Society of Anesthesiology (ASA) classification, principal Current Procedural Terminology (CPT) and International Classification of Diseases, $9^{\text {th }}$ Edition, Clinical Modification (ICD-9 CM) codes, and operative 
information were utilized to characterize patients. Individual medical record numbers were matched to the BWH laboratory database to determine pre-operative random glucose measurements. Post-operative insulin treatment was determined from BWH medical records. The primary independent variable for the study was defined as the last glucose (in the clinical lab or as point of care (POC) testing) measured within 30 days prior to surgery. The study was approved by the BWH/Partners Institutional Review Board.

\section{Outcome measures}

The primary outcome was post-operative infection rate as defined by the percentage with any occurrences from a composite list of post-operative infections within 30 days, based on NSQIP data and definition. ${ }^{20}$ Post-operative infections have been associated with prolonged hospitalization, increased readmission, and increased cost. ${ }^{21}$ Following previous research, ${ }^{10}$ we used a composite of superficial incisional surgical site infection (SSI), deep incisional SSI, organ space SSI, wound disruption, graft/prosthesis/flap failure, pneumonia, urinary tract infection, sepsis, and septic shock. Secondary outcomes included the number of composite post-operative infections, and the rate and number of all NSQIP-identified post-operative complications including unplanned intubation, pulmonary embolism, on ventilator $>48 \mathrm{hrs,} \mathrm{progressive} \mathrm{renal}$ insufficiency, acute renal failure, stroke, coma, peripheral nerve injury, cardiac arrest requiring cardio-pulmonary resuscitation, myocardial infarction, bleeding/transfusions, and deep vein thrombosis. In our one year follow-up, we classified patients as having had pre-diabetes at the time of surgery as those with evidence of diabetic diagnoses within the following year. Diabetic diagnosis was defined by retrospective review of hospital and outpatient records from the Partners Healthcare Clinical Data Repository using the following criteria: $\mathrm{HbA} 1 \mathrm{c} \geq 6.5$, billing 
diagnosis of diabetes (ICD-9 CM 250.xx), use of anti-hyperglycemic medications, or outpatient problem of diabetes in the outpatient medical record.

\section{Analysis and statistical methods}

All statistical analyses were performed using Stata 12. Clinical characteristics of the patient population included in this study were described for the entire sample and as a comparison between patients who had any post-operative infection and those who did not. These comparisons were conducted with t-tests for samples of unequal variances or Fisher's exact test as appropriate. Next, post-operative infection rates were calculated for patient groups according to pre-operative glucose levels. Patients were classified into 5 groups based on clinically relevant cut-off points: pre-operative glucose $<70 \mathrm{mg} / \mathrm{dL}, 70-99 \mathrm{mg} / \mathrm{dL}, 100-139 \mathrm{mg} / \mathrm{dL}, 140-179 \mathrm{mg} / \mathrm{dL}$, and $\geq 180 \mathrm{mg} / \mathrm{dL}$. The glucose level stratification was based on a composite of current ADA recommendations for diagnosis of pre-diabetes and diabetes including both random and fasting values. These are also cut points considered for treatment with insulin in the inpatient setting under various circumstances (e.g., ICU vs. ward vs. ward with risk factors for hypoglycemia). These stratifications were used in the first parts of our analyses to estimate any trends in the relationship, before we proceeded to using multivariable logistic regressions to model the incremental relationship and adjust for other risk factors. Likelihood ratio tests were used to determine overall differences among groups, and t-tests were used to determine differences between individual groups. The same analyses were performed for the secondary outcome measures. Before proceeding to logistic regression to assess pre-operative glucose as a screening tool while controlling for other clinical characteristics, an analysis for threshold and non-linear effects of pre-operative glucose on infection rates was conducted using a cubic spline model. One identified non-linear range (patients with pre-operative glucose $\geq 180 \mathrm{mg} / \mathrm{dL}$ ) was then 
assessed for confounding by indication by comparing post-operative insulin use using logistic regression.

After identifying a reliable range for logistic modeling, a multivariate model was used to estimate the relationship of pre-operative glucose as a marker for post-operative infection rate to assess the former as a potential screening tool when combined with other clinical characteristics. The risk adjusted logistic model controlled for age, gender, BMI, ASA classification, and type of surgery (gastric bypass, colectomy, hepatectomy, cholecystectomy, pancreatectomy, hernia, AAA, bypass graft). The same adjusted analysis was performed on the secondary outcomes. The 1-year followup data was used to identify patients within our study cohort who may have had pre-diabetes or undiagnosed diabetes prior to surgery. We analyzed the post-operative infection rates among these patients, and analyzed the relationship between pre-operative glucose and post-operative infection rates among pre-diabetic and non-pre-diabetic patients.

\section{RESULTS}

Of 10,812 patients with non-emergent surgery at BWH during the study period, 8,154 (75\%) had a pre-operative glucose level within 30 days of surgery. We excluded 1,204 patients with a known diagnosis of diabetes and 267 patients with pre-operative sepsis, leaving 6,683 patients in the final study cohort. The study characteristics for the entire cohort are shown in Table 1. Overall, the mean age of the patients was 54.6 years and $34 \%$ were male. 6,037 (90\%) underwent general surgery and $646(10 \%)$ underwent vascular surgery. 2,524 (38\%) had a body mass index $(\mathrm{BMI})>30$ and $69(1 \%)$ were in ASA class 4 or 5 . Patients with post-operative infection were more likely to be male, be older, have longer operation time, have higher preoperative glucose, and have a diagnosis of diabetes within 1 year post surgery. The type of surgery and ASA classification prior to surgery were also significantly different between patients 
with and without post-operative infection. The vast majority of pre-operative glucose measurements were from laboratory blood glucose testing, with 147 (2.2\%) of the pre-operative glucose levels coming from POC measurements. The last pre-operative glucose measurements were taken on average 8 days prior to surgery, with $16 \%$ within 1 day and $29 \%$ within 3 days prior to surgery (Figure 1). Excluded patients were more likely to be older (55.4 vs. 54.6 years, $\mathrm{P}<0.05$ ), have shorter operation time (121 vs. $141, \mathrm{P}<0.001)$, shorter days of stay (3.5 vs. 4 , $\mathrm{P}<0.001)$, and lower post-operative infection rate (4.8\% vs. $6.7 \%, \mathrm{P}<0.001)$. Of these, patients excluded due to lack of glucose measurement within 30 days prior to surgery were younger (53.6 vs. 54.6, $\mathrm{P}<0.01)$, more likely to have ASA classification of 1 or $2(76.7 \%$ vs. $67.8 \%, \mathrm{P}<0.001)$, had lower BMI (28 vs. 30, $\mathrm{P}<0.001$ ), shorter days of stay (2 vs. 4, $\mathrm{P}<0.001$ ), shorter length of operation (106 vs. 141 minutes, $\mathrm{P}<0.001)$, and lower post-operative infection rate (3.0\% vs. $6.7 \%, \mathrm{P}<0.001)$

\section{Comparison of post-operative outcomes by pre-operative glucose levels}

Dividing the sample into five groups based on their pre-operative glucose levels, patients with glucose levels $<70 \mathrm{mg} / \mathrm{dL}, 70-99 \mathrm{mg} / \mathrm{dL}, 100-139 \mathrm{mg} / \mathrm{dL}, 140-179 \mathrm{mg} / \mathrm{dL}$, and $\geq 180 \mathrm{mg} / \mathrm{dL}$ had post-operative infection rates of $5.47 \%, 5.62 \%, 9.33 \%, 10.16 \%$, and $6.67 \%$ respectively

(Figure 2). Logistic likelihood ratio test on the primary outcome of post-operative infection rates showed significant differences among groups $(\mathrm{P}<0.001)$, with the $100-139 \mathrm{mg} / \mathrm{dL}$ and $140-179$ $\mathrm{mg} / \mathrm{dL}$ groups having significantly higher post-operative infection rates than the normo-glycemic group (70-99 mg/dL). The group with the highest pre-operative glucose ( $\geq 180 \mathrm{mg} / \mathrm{dL}$ ) did not have a statistically significant difference in infection rates from the normo-glycemic group. 
Similar trends were seen for total complication rates, mean number of infections and mean number of complications per patient. All three outcomes are more common with increasing levels of pre-operative glucose up to $180 \mathrm{mg} / \mathrm{dL}$ (Table 2).

\section{Estimating the magnitude of effect of pre-operative glucose on post-operative outcomes}

The cubic spline model (overlay in Figure 2) has flexibility to allow for possible threshold and non-linear effects. This model indicated non-linearity for patients with preoperative glucose at the low extreme $(<70 \mathrm{mg} / \mathrm{dL})$ and the high extreme $(\geq 180 \mathrm{mg} / \mathrm{dL})$. Regarding potential confounding by indication in cases of extreme hyperglycemia (e.g., patients doing better because providers chose to treat these patients with insulin after noticing their hyperglycemia), we found that the odds of post-operative insulin treatment in the highest preoperative glucose ( $\geq 180 \mathrm{mg} / \mathrm{dL}$ ) group was 8.04 (95\% CI, 3.57-18.10) times that of the rest of the patients in our sample $(\mathrm{P}<0.001)$. Of note, in these 60 patients, 5\% had ASA classification 1, 40\% had ASA classification 2, 53\% had ASA classification 3, 2\% had ASA classification 4, and $60 \%$ went on to develop diabetes during the following year according to our records. Over the range of pre-operative glucose between 70 and $180 \mathrm{mg} / \mathrm{dL}$, the cubic spline model indicated a continuous trend that could be well-estimated by logistic regression models. Therefore, to quantify the relationship of hyperglycemia as a marker of post-operative complications and minimize the effects of confounding by indication, we proceeded by focusing on the range of patients with pre-operative glucose $\geq 70 \mathrm{mg} / \mathrm{dL}$ and $<180 \mathrm{mg} / \mathrm{dL}$ ( $93 \%$ of the entire sample).

The risk adjusted logistic model (Table 3) controls for basic clinical characteristics as well as disease severity, indicating a 40\% (95\% CI, 13\%-72\%) increase in the odds of infection for each $40 \mathrm{mg} / \mathrm{dL}$ in pre-operative glucose $(\mathrm{P}=0.002)$. Figure 3 is a graphical representation of pre-operative glucose as a marker for post-operative infection rate after risk adjustment. The risk 
adjusted models for each type of infection showed non-statistically significant trends for increased risk of infection with hyperglycemia, except for superficial SSI where the relationship was statistically significant (Table 4).

Similar results were demonstrated for the secondary outcome measures: $42 \%$ (95\% CI, 21\%-68\%) increased odds of infection ( $\mathrm{P}<0.001), 24$ (95\% CI, 5-43) more infections per 1000 patients $(\mathrm{P}=0.014)$, and $71(95 \% \mathrm{CI}, 35-107)$ more complications per 1000 patients $(\mathrm{P}<0.001)$ per $40 \mathrm{mg} / \mathrm{dL}$ increase in pre-operative glucose after risk adjustment.

\section{One year follow-up on diabetic status}

Of the entire study population, 547 patients $(8.18 \%)$ were identified as diabetic one year later, including 314 patients (15.33\%) of those with pre-operative glucose $\geq 100 \mathrm{mg} / \mathrm{dL}$. This group of 547 will be identified below as "pre-diabetic" while the others are classified as "nonpre-diabetic". Those who were (retrospectively) identified as pre-diabetic at the time of the operation had significantly higher infection rates $(9.32 \%)$ than those who were not identified as diabetic one year later $(6.52 \%, \mathrm{P}=0.012)$.

Within the pre-diabetic group, there is no statistically significant relationship for preoperative glucose as a marker of post-operative infection rate $(6.6 \%$ increase in odds per 40 $\mathrm{mg} / \mathrm{dL}$ increase in pre-operative glucose, $95 \% \mathrm{CI}-36 \%$ to $78 \%$ ). Within the much larger nonpre-diabetic group, there was a risk adjusted $41 \%$ increase in the odds of post-operative infection per $40 \mathrm{mg} / \mathrm{dL}$ increase in pre-operative glucose (95\% CI $12 \%$ to $78 \%, \mathrm{P}=0.004)$.

\section{DISCUSSION}

Our study shows that pre-operative blood glucose in patients without known diabetes can be a useful marker to screen for complications after non-emergent operations, even after 
adjusting for basic clinical characteristics and disease severity. Though there likely are many confounding factors in this relationship, we were interested in pre-operative glucose as a screening tool instead of establishing any causal or independent relationship. Patients without "known diabetes" (as defined by NSQIP, i.e., anyone not taking oral hypoglycemic agents or insulin) may have had hyperglycemia due to undiagnosed diabetes, diabetes controlled by diet only, pre-diabetes, or illnesses causing physiologic stress. We excluded patients with known diabetes as treatment is likely to confound the findings and pre-operative testing is more common, and emergent cases, where pre-operative screenings may not be possible and physiological stress is often more apparent. Ramos et al. found that pre-operative glucose level did not predict post-operative infection if post-operative glucose level is known, ${ }^{10}$ however, our study is interested in proactive, pre-operative identification of patients at risk since this may lead to better intra- and post-operative care and may lead to diagnosis of underlying diabetes or prediabetes prior to surgery.

Our main results suggest that blood glucose should be considered as one of the preoperative screening measures for patients without known diabetes, as a marker for worse postoperative outcomes and for identification of patients with pre-diabetes and undiagnosed diabetes. One of the most interesting findings of our study is the fact that patients with random mild hyperglycemia (pre-operative glucose level of 100-139 mg/dL), which many surgeons may accept as normal, did indeed have an increased risk of post-operative infections and other postoperative complications. We would recommend checking an HbA1c in these patients preoperatively to identify patients with previously undiagnosed diabetes or pre-diabetes (HbAlc 5.8-6.4). Once these patients are identified, we recommend looking for possible sources of physiological stress (e.g., review of systems and physical exam for symptoms and signs of 
infection, urinalysis and chest $\mathrm{x}$-ray if warranted), close monitoring of glucose levels immediately before, during, and after surgery, a low threshold for treating with physiological doses of insulin (e.g., if glucose $>140 \mathrm{mg} / \mathrm{dL}$ ), and outpatient follow-up for the development of diabetes in the following year (e.g., HbA1c every 3 months). The number of patients in the group with pre-operative glucose $>180 \mathrm{mg} / \mathrm{dL}$ was too small to show any significant difference in postoperative infection and complication rates. Treatment with insulin may have confounded the relationship between glucose levels and infection rates. Many likely had underlying physiological stress, although this is difficult to prove. Similarly, patients with pre-operative glucose $<70 \mathrm{mg} / \mathrm{dL}$ did not have significant differences in post-operative complication rates, but did trend higher than patients with pre-operative glucose between $70-99 \mathrm{mg} / \mathrm{dL}$, raising the implications of mild hypoglycemia as another possible area to investigate in further studies. There has been controversy regarding perioperative glycemic control. ${ }^{22-26}$ Some evidence supports implementing glycemic control prior to surgery, ${ }^{27,28}$ which suggests that delaying surgery for better glycemic control in the cases of elective surgeries may be a useful option. A randomized prospective study would be needed to address the best course of action once patients without known diabetes are pre-operatively screened for glucose. Regardless of the causal factors, our findings raise the possibility that pre-operative hyperglycemia is a modifiable risk marker, for which monitoring and management may improve post-operative outcomes.

Upon follow-up, those who were pre-diabetic at the time of surgery had worse postoperative outcomes than those who were not, further emphasizing the need for identifying those who are pre-diabetic prior to surgery (e.g., with an HbA1c measurement) and may be at increased risk for post-operative complications. These patients may also need long-term surveillance and management. Increasing pre-operative glucose in those who did not go on to 
develop diabetes, i.e., those who possibly had "stress" hyperglycemia, ${ }^{1,2}$ was associated with increasing risks of post-operative infection, showing that there may be an important pathophysiologic process requiring further investigation and treatment. Our sample size did not give us enough power to estimate this effect in those with pre-diabetes and we cannot exclude the possibility that those who were pre-diabetic also suffered from stress as a cause of their hyperglycemia, at least in part. In patients with pre-operative glucose $\geq 100 \mathrm{mg} / \mathrm{dL}, 15 \%$ were diagnosed with diabetes over the next year, but $85 \%$ were not, suggesting that stress hyperglycemia may be far more common than undiagnosed diabetes, at least within the limits of our ability to detect diabetes on follow-up.

In comparison, reports utilizing pre-operative $\mathrm{HbA} 1 \mathrm{c}$ found increased risk of deep sternal wound infection after CABG when controlling for diabetes diagnosis, ${ }^{29}$ higher post-operative complications after colorectal surgery in patients without known diabetes, ${ }^{30}$ increased 30 -day morbidity in patients without diabetes undergoing vascular surgery, ${ }^{31}$ but no association with post-operative infection risk in non-diabetic cardiac surgery patients, ${ }^{32}$ with increased HbA1c levels. The patients included in our study had no known diabetes, and HbA1c measurements were not available. We also feel that glucose would be useful to identify patients with recent hyperglycemia (i.e., due to physiological stress). We advocate for a policy to routinely measure pre-operative glucose and identify patients with poor glucose control so that follow-up HbA1c testing and other interventions could be initiated prior to surgery as this practice is not yet a routine pre-operative screening tool at many hospitals. In patients with a diagnosis of diabetes, studies have been mixed, showing that pre-operative hyperglycemia is not associated with mortality or infection rates in non-cardiac surgery, ${ }^{9,17}$ but also that increased pre-operative glucose is associated with higher mortality in patients undergoing non-cardiac non-vascular 
surgery, ${ }^{11}$ and that operative day hyperglycemia is associated with SSI after colectomy for cancer. $^{33}$

Our study had several limitations. Due to the retrospective nature of its design, 2,658 patients did not have a record of blood glucose measurement within 30 days prior to their operations and so could not be included in the study. Our conclusions are based on patients who did have a pre-operative glucose measurement. Physicians may have had clinical reasons for not ordering pre-operative glucose for some patients, likely because they did not believe these patients would be at risk for hyperglycemia. However, though not routine, glucose testing is often obtained pre-operative evaluation, as witnessed by the fact that $75 \%$ of our cohort did have a pre-operative glucose value and that most glucose values were still normal. Thus, while there may be some bias in the absolute proportion of patients in our cohort found to have hyperglycemia ( $22 \%$ instead of $31 \%$ if all untested patients had normo-glycemia), it is unlikely that the relationship between pre-operative glucose levels and outcomes is substantially different in the minority of patients without pre-operative glucose readings. One might argue that the exclusion of these patients from the study limits the generalizability of the findings to these healthiest of patients, but their exclusion does not bias our regression coefficients. Our findings in fact suggest that excluded patients had fewer risk factors for hyperglycemia, better clinical outcomes, and were less likely to have post-operative infections, thus would strengthen our conclusions if they had been included. In terms of data gathering, as glucose levels were randomly obtained we cannot distinguish which of the hyperglycemic group actually had what would be considered normal post-prandial values. If anything, this would bias our findings towards the null. In addition, ACS NSQIP does not capture a small number of patients with diabetes controlled on diet only (i.e., who should not have been included in the study); it is 
unlikely that these patients substantially altered our findings. The severity and physiological stress of our patients were not completely adjusted for in our study by the ASA classification and type of surgery, as the acute physiology score was not readily available in the databases we used. In terms of follow-up data, since the pre-operative and follow-up data were obtained from the Partners Clinical Data Repository, we may have underestimated the proportion of patients with diagnosed diabetes within one year. Lastly, the generalizability of our results may be limited as our study was conducted at a large academic medical center. Nevertheless, our sample is drawn from a large urban teaching hospital with a diverse patient population. In future studies, we hope to include multi-site prospective analyses and greater sample size for sub-group analyses and with more complete follow-up on diabetic status.

In conclusion, we found that in patients not known to have diabetes, increasing random pre-operative glucose is a marker for worsening post-operative outcomes, an effect that holds true after adjusting for other clinical screening measures and over even mild to moderate degrees of hyperglycemia. Whether pre-operative hyperglycemia is a marker for other factors that influence post-operative outcomes or is an independent factor, pre-operative glucose remains a metric that is easily obtainable and actionable. Our results suggest that blood glucose measurements should be taken routinely for patients without known diabetes prior to nonemergent surgery. For those noted to be hyperglycemic, future studies may indicate delaying surgery to improve glycemic control, perioperative glucose monitoring and treatment, a search for previously unknown causes of physiologic stress, as well as follow up with patients after surgery for the development of diabetes mellitus. We recommend that future studies should use prospective methods and randomized multi-centered controlled trials to test for the effectiveness 
of pre-operative screening for hyperglycemia as a way to improve patient outcomes in the immediate post-operative period and beyond. 


\section{References}

1. Umpierrez GE, Isaacs SD, Bazargan N, You X, Thaler LM, Kitabchi AE. Hyperglycemia: an independent marker of in-hospital mortality in patients with undiagnosed diabetes. J Clin Endocrinol Metab 2002; 87(3):978-982.

2. Kerby JD, Griffin RL, MacLennan P, et al. Stress-induced hyperglycemia, not diabetic hyperglycemia, is associated with higher mortality in trauma. Ann Surg 2012; 256(3):446-452.

3. Kosiborod M, Rathore SS, Inzucchi SE, Masoudi FA, Wang Y, Havranek EP, Krumholz HM. Admission glucose and mortality in elderly patients hospitalized with acute myocardial infarction. Circulation 2005; 111(23):3078-3086.

4. Furnary AP, Gao G, Grunkemeier GL, et al. Continuous insulin infusion reduces mortality in patients with diabetes undergoing coronary artery bypass grafting. $\mathrm{J}$ Thorac Cardiovasc Surg 2003; 125(5):1007-1021.

5. van den Berghe G, Wouters P, Weekers F, et al. Intensive insulin therapy in the critically ill patients. N Engl J Med 2001; 345(19):1359-1367.

6. Schmeltz LR, DeSantis AJ, Thiyagarajan V, et al. Reduction of surgical mortality and morbidity in diabetic patients undergoing cardiac surgery with a combined intravenous and subcutaneous insulin glucose management strategy. Diabetes Care 2007; 30(4):823828

7. Hruska LA, Smith JM, Hendy MP, Fritz VL, McAdams S. Continuous insulin infusion reduces infectious complications in diabetics following coronary surgery. J Card Surg 2005; 20(5):403-407. 
8. Umpierrez GE, Smiley D, Jacobs S et al. Randomized study of basal-bolus insulin therapy in the inpatient management of patients with type 2 diabetes undergoing general surgery (RABBIT 2 Surgery). Diabetes Care 2011; 34(2):256-261.

9. King JT, Goulet JL, Perkal MF, Rosenthal RA. Glycemic control and infections in patients with diabetes undergoing noncardiac surgery. Ann Surg. 2011;253(1):158-165.

10. Ramos M, Khalpey Z, Lipsitz S, et al. Relationship of perioperative hyperglycemia and postoperative infections in patients who undergo general and vascular surgery. Ann Surg 2008; 248(4):585-591.

11. Noordzij PG, Boersma E, Schreiner F, et al. Increased preoperative glucose levels are associated with perioperative mortality in patients undergoing noncardiac, nonvascular surgery. Eur J Endocrinol 2007; 156(1):137-142.

12. Sperry JL, Frankel HL, Vanek SL, et al. Early hyperglycemia predicts multiple organ failure and mortality but not infection. J Trauma 2007; 63(3):487- 493.

13. Sima AA, O’Neill SJ, Naimark D, et al. Bacterial phagocytosis and intracellular killing by alveolar macrophages in BB rats. Diabetes 1988; 37(5):544-549.

14. Bagdade JD, Root RK, Bulger RJ. Impaired leukocyte function in patients with poorly controlled diabetes. Diabetes 1974; 23(1):9-15.

15. Black CT, Hennessey PJ, Andrassy RJ. Short-term hyperglycemia depresses immunity through nonenzymatic glycosylation of circulating immunoglobulin. J Trauma 1990; $30(7): 830-833$.

16. Hennessey PJ, Black CT, Andrassy RJ. Nonenzymatic glycosylation of immunoglobulin G impairs complement fixation. J Parenter Enter Nutr 1991; 15(1):60-64. 
17. Frisch A, Chandra P, Smiley D, et al. Prevalence and clinical outcome of hyperglycaemia in the perioperative period in noncardiac surgery. Diabetes Care 2010; 33(8):1783-1788.

18. McGirt MJ, Woodworth GF, Ali M, Than KD, Tamargo RJ, Clatterbuck RE. Persistent perioperative hyperglycemia as an independent predictor of poor outcome after aneurismal subarachnoid hemorrhage. J Neurosurg 2007; 107(6):1080-1085.

19. Zhang P, Engelgau MM, Valdez R, Cadwell B, Benjamin SM, Narayan KM. Efficient cutoff points for three screening tests for detecting undiagnosed diabetes and prediabetes: an economic analysis. Diabetes Care 2005; 28(6):1321-1325.

20. ACS NSQIP. User Guide for the 2009 Participant Use Data File. October 2010. http://site.acsnsqip.org/wpcontent/uploads/2012/03/ACS_NSQIP_Participant_User_Data_File_User_Guide.pdf

21. Herwaldt LA, Cullen JJ, Scholz D, French P, Zimmerman MB, Pfaller MA, Wenzel RP, Perl TM. A prospective study of outcomes, healthcare resource utilization, and costs associated with postoperative nosocomial infections. Infect Control Hosp Epidemiol 2006; 27(12):1291-1298.

22. Giakoumidakis K, Eltheni R, Patelarou E, Theologou S, Patris V, Michopanou N, Mikropoulos T, Brokalaki H. Effects of intensive glycemic control on outcomes of cardiac surgery. Heart Lung 2013; 42(2):146-151.

23. Kwon S, Thompson R, Dellinger P, Yanez D, Farrohki E, Flum D. Importance of perioperative glycemic control in general surgery: a report from the Surgical Care and Outcomes Assessment Program. Ann Surg 2013; 257(1);8-14.

24. Russo N. Perioperative glycemic control. Anesthesiol Clin 2012; 30(3):445-466. 
25. Duncan AE. Hyperglycemia and perioperative glucose management. Curr Pharm Des 2012; 18(38):6195-6203.

26. Pichardo-Lowden A, Gabbay RA. Management of hyperglycemia during the perioperative period. Curr Diab Rep 2012; 12(1):108-118.

27. Tully V, Wolever TM, Darling P, Errett L, Keith ME. Pre-operative modification of dietary glycemic index improves pre but not post-operative indices of insulin resistance in patients undergoing coronary artery bypass graft surgery. J Am Coll Nutr 2008; 27(1):168-176.

28. Patel VC, Aldridge RD, Leeds A, Dornhorst A, Frost GS. Retrospective analysis of the impact of a low glycaemic index diet on hospital stay following coronary artery bypass grafting: a hypothesis. J Hum Nutr Diet 2004; 17(3):241-247.

29. Halkos ME, Puskas JD, Lattouf OM, Kilgo P, Kerendi F, Song HK, Guyton RA, Thourani VH. Elevated preoperative hemoglobin A1c level is predictive of adverse events after coronary artery bypass surgery. J Thorac Cardiovasc Surg 2008; 136(3):631640.

30. Gustafsson UO, Thorell A, Soop M, Ljungqvist O, Nygren J. Haemoglobin A1c as a predictor of postoperative hyperglycaemia and complications after major colorectal surgery. Br J Surg 2009; 96(11):1358-1364.

31. O'Sullivan CJ, Hynes N, Mahendran B, Andrews EJ, Avalos G, Tawfik S, Lowery A, Sultan S. Haemoglobin A1c (HbA1C) in non-diabetic and diabetic vascular patients. Is $\mathrm{HbA1C}$ an independent risk factor and predictor of adverse outcome? Eur J Vasc Endovasc Surg 2006; 32(2):188-197. 
32. Hudson CC, Welsby IJ, Phillips-Bute B, Mathew JP, Lutz A, Chad Hughes G, StaffordSmith M; Cardiothoracic Anesthesiology Research Endeavors (C.A.R.E.) Group. Glycosylated hemoglobin levels and outcome in non-diabetic cardiac surgery patients. Can J Anaesth 2010; 57(6):565-572.

33. Jackson RS, Amdur RL, White JC, Macsata RA. Hyperglycemia is associated with increased risk of morbidity and mortality after colectomy for cancer. J Am Coll Surg $2012 ; 214(1): 68-80$. 
Table 1 - Clinical characteristics of the study participants

\begin{tabular}{|c|c|c|c|c|}
\hline Variable & All & $\begin{array}{l}\text { Patients with } \\
\text { post- } \\
\text { operative } \\
\text { infection }\end{array}$ & $\begin{array}{c}\text { Patients } \\
\text { without post- } \\
\text { operative } \\
\text { infection }\end{array}$ & $P$ value \\
\hline$\overline{\mathrm{N}}$ & 6,683 & $451(6.7)$ & $6,232(93.3)$ & \\
\hline Male & $2,276(34.1)$ & $212(47.0)$ & $2,064(33.1)$ & $<0.001$ \\
\hline Mean age, years & $54.6 \pm 15.9$ & $57.3 \pm 16.1$ & $54.5 \pm 15.9$ & $<0.001$ \\
\hline Mean BMI & $30.4 \pm 9.7$ & $29.6 \pm 8.8$ & $30.5 \pm 9.7$ & 0.062 \\
\hline \multicolumn{5}{|l|}{ Race } \\
\hline American Indian/ Alaskan Native & $3(0.04)$ & 0 & $3(0.05)$ & \multirow{6}{*}{$\begin{array}{c}0.738 \\
\text { (F test) }\end{array}$} \\
\hline Asian & $93(1.4)$ & 7 (1.6) & $86(1.4)$ & \\
\hline Black/African American & $507(7.6)$ & $27(6.0)$ & $480(7.7)$ & \\
\hline Native Hawaiian/ Pacific Islander & $2(0.03)$ & 0 & $2(0.03)$ & \\
\hline White & $5,297(79.3)$ & $365(80.9)$ & $4,932(79.1)$ & \\
\hline Hispanic & $400(6.0)$ & $31(6.9)$ & $369(5.9)$ & \\
\hline \multicolumn{5}{|l|}{ Type of surgery } \\
\hline Gastric Bypass & $1,227(18.4)$ & $51(11.3)$ & $1,176(18.9)$ & \multirow{9}{*}{$\begin{array}{l}<0.001 \\
(\mathrm{~F} \text { test })\end{array}$} \\
\hline Colectomy & $1,400(20.9)$ & $169(37.5)$ & $1,231(19.8)$ & \\
\hline Hepatectomy & 109 (1.6) & $21(4.7)$ & $88(1.4)$ & \\
\hline Cholecystectomy & $346(5.2)$ & $12(2.7)$ & $334(5.4)$ & \\
\hline Pancreatectomy & $116(1.7)$ & $23(5.1)$ & $93(1.5)$ & \\
\hline Hernia & $246(3.7)$ & $13(2.9)$ & $233(3.7)$ & \\
\hline Amputation & $39(0.6)$ & 0 & $39(0.6)$ & \\
\hline AAA & $82(1.2)$ & $4(0.9)$ & $78(1.3)$ & \\
\hline Bypass graft & $51(0.8)$ & $8(1.8)$ & $43(0.7)$ & \\
\hline Length of Stay, days & $4.4 \pm 7.3$ & $12.6 \pm 12.0$ & $3.8 \pm 6.5$ & $<0.001$ \\
\hline Mean Op Time, minutes & $141 \pm 100$ & $217 \pm 128$ & $136 \pm 95$ & $<0.001$ \\
\hline \multicolumn{5}{|l|}{ ASA Classification } \\
\hline 1 & $362(5.4)$ & $10(2.2)$ & $352(5.6)$ & \multirow{6}{*}{$\begin{array}{l}<0.001 \\
(\mathrm{~F} \text { test })\end{array}$} \\
\hline 2 & $4,170(62.4)$ & $205(45.5)$ & $3,965(63.6)$ & \\
\hline 3 & $2,076(31.1)$ & $229(50.8)$ & $1,847(29.6)$ & \\
\hline 4 & $68(1.0)$ & 7 (1.6) & $61(1.0)$ & \\
\hline 5 & $1(0.01)$ & 0 & $1(0.02)$ & \\
\hline None & $6(0.09)$ & 0 & $6(0.1)$ & \\
\hline $\begin{array}{l}\text { Pre-operative glucose within } 30 \text { days, } \\
\mathrm{mg} / \mathrm{dL}\end{array}$ & $94.9 \pm 22.4$ & $99.3 \pm 23.3$ & $94.6 \pm 22.3$ & $<0.001$ \\
\hline Diagnosis of diabetes within 1 year & $547(8.18)$ & $51(11.3)$ & $496(8.0)$ & 0.029 \\
\hline
\end{tabular}

Data are presented as mean \pm standard deviation or $\mathrm{n}(\%)$ unless otherwise indicated. 
Table 2 - Outcome comparisons among patient groups by pre-operative glucose levels

\begin{tabular}{lcccccc}
\hline $\begin{array}{l}\text { Patient groups by } \\
\text { pre-operative } \\
\text { glucose levels }\end{array}$ & $\begin{array}{c}\mathrm{mg} / \mathrm{dL} \\
(\mathrm{N}=384)\end{array}$ & $\begin{array}{c}70-99 \\
\mathrm{mg} / \mathrm{dL} \\
(\mathrm{N}=4251)\end{array}$ & $\begin{array}{c}100-139 \\
\mathrm{mg} / \mathrm{dL} \\
(\mathrm{N}=1801)\end{array}$ & $\begin{array}{c}140-179 \\
\mathrm{mg} / \mathrm{dL} \\
(\mathrm{N}=187)\end{array}$ & $\begin{array}{r}\geq 180 \\
\mathrm{mg} / \mathrm{dL} \\
(\mathrm{N}=60)\end{array}$ & \\
\hline Infection rate & $5.47 \%$ & $5.62 \%$ & $9.33 \%$ & $10.16 \%$ & $6.67 \%$ & $\mathrm{P}<0.001$ \\
\hline Complication rate & $10.68 \%$ & $10.84 \%$ & $17.93 \%$ & $20.32 \%$ & $13.33 \%$ & $\mathrm{P}<0.001$ \\
\hline $\begin{array}{l}\text { Infections } \\
\text { (per 1,000) }\end{array}$ & 68 & 70 & 113 & 123 & 66 & $\mathrm{P}<0.001$ \\
\hline $\begin{array}{l}\text { Complications } \\
\text { (per 1,000) }\end{array}$ & 148 & 163 & 291 & 353 & 233 & $\mathrm{P}<0.001$ \\
\hline
\end{tabular}


Table 3 - Adjusted logistic model of pre-operative glucose, over the range of 70-179 mg/dl, as a marker of post-operative infection

\begin{tabular}{lcc}
\hline Variable & OR (95\% CI) & P value \\
\hline Pre-operative glucose (per $4 \mathbf{~ m g / d L )}$ & $\mathbf{1 . 4 0}(\mathbf{1 . 1 3}-\mathbf{1 . 7 2})$ & $\mathbf{0 . 0 0 2}$ \\
Age (per year) & $0.99(0.99-1.00)$ & 0.169 \\
Male & $1.40(1.14-1.72)$ & 0.001 \\
BMI (per unit) & $1.02(1.00-1.03)$ & 0.042 \\
ASA Class (per increase in category) & $1.90(1.58-2.29)$ & $<0.001$ \\
Gastric bypass & $0.63(0.40-1.00)$ & 0.052 \\
Colectomy & $2.56(2.02-3.24)$ & $<0.001$ \\
Hepatectomy & $3.94(2.33-6.66)$ & $<0.001$ \\
Cholecystectomy & $0.75(0.40-1.41)$ & 0.368 \\
Pancreatectomy & $4.11(2.43-6.95)$ & $<0.001$ \\
Hernia & $1.00(0.54-1.85)$ & 0.994 \\
AAA & $0.52(0.16-1.69)$ & 0.275 \\
Bypass graft & $2.99(1.35-6.60)$ & 0.007 \\
\hline BMI: body mass
\end{tabular}

BMI: body mass index; ASA: American Society of Anesthesiology; AAA: abdominal aortic aneurysm. 
Table 4 - Adjusted logistic models of pre-operative glucose, over the range of 70-179 mg/dl, as a marker of each category of post-operative infection

\begin{tabular}{lcc}
\hline Category of post-operative infection* & $\begin{array}{l}\text { Pre-op glucose }(\text { per } 40 \mathrm{mg} / \mathrm{dL}) \\
\text { OR }(95 \% \mathrm{CI})\end{array}$ & P value \\
\hline Superficial incisional SSI & $1.56(1.16-2.10)$ & 0.003 \\
Deep incisional SSI & $1.17(0.34-4.02)$ & 0.802 \\
Organ space SSI & $1.57(0.97-2.53)$ & 0.065 \\
Wound disruption & $1.18(0.97-3.04)$ & 0.726 \\
Graft/prosthesis/flap & $0.68(0.97-4.24)$ & 0.676 \\
Pneumonia & $1.17(0.70-1.96)$ & 0.549 \\
Urinary tract infection & $0.53(0.28-1.02)$ & 0.057 \\
Sepsis & $1.46(0.97-2.19)$ & 0.068 \\
Septic shock & $0.85(0.41-1.79)$ & 0.677 \\
\hline
\end{tabular}

* All models adjusted for age, gender, BMI, ASA classification, type of surgery (gastric bypass, colectomy, hepatectomy, cholecystectomy, pancreatectomy, hernia, AAA, bypass graft). 


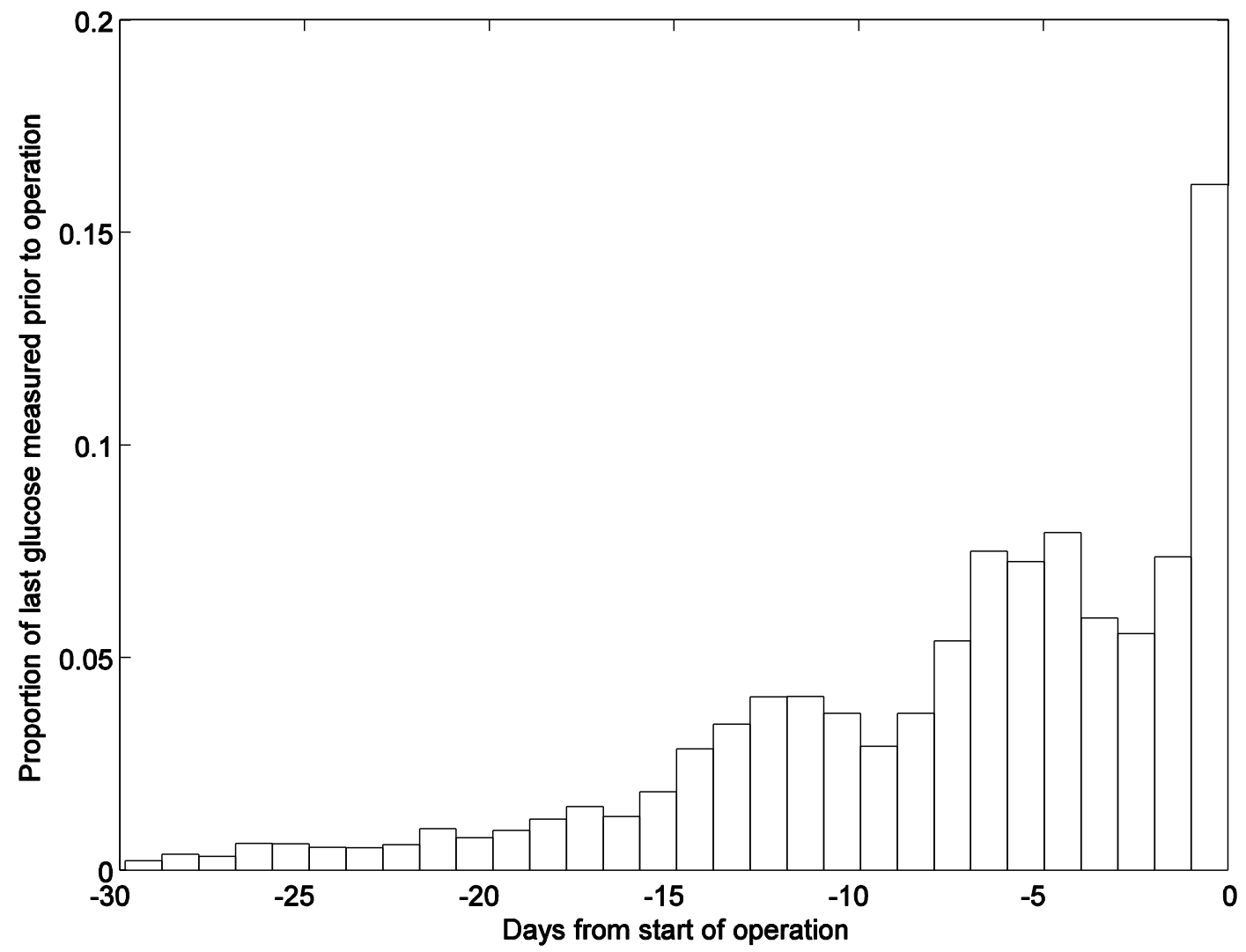

Figure 1 - Distribution of last glucose measured pre-operatively by days from start of operation (ex. measurements within 24 hours prior to the start of operation fall between -1 and 0 ). 


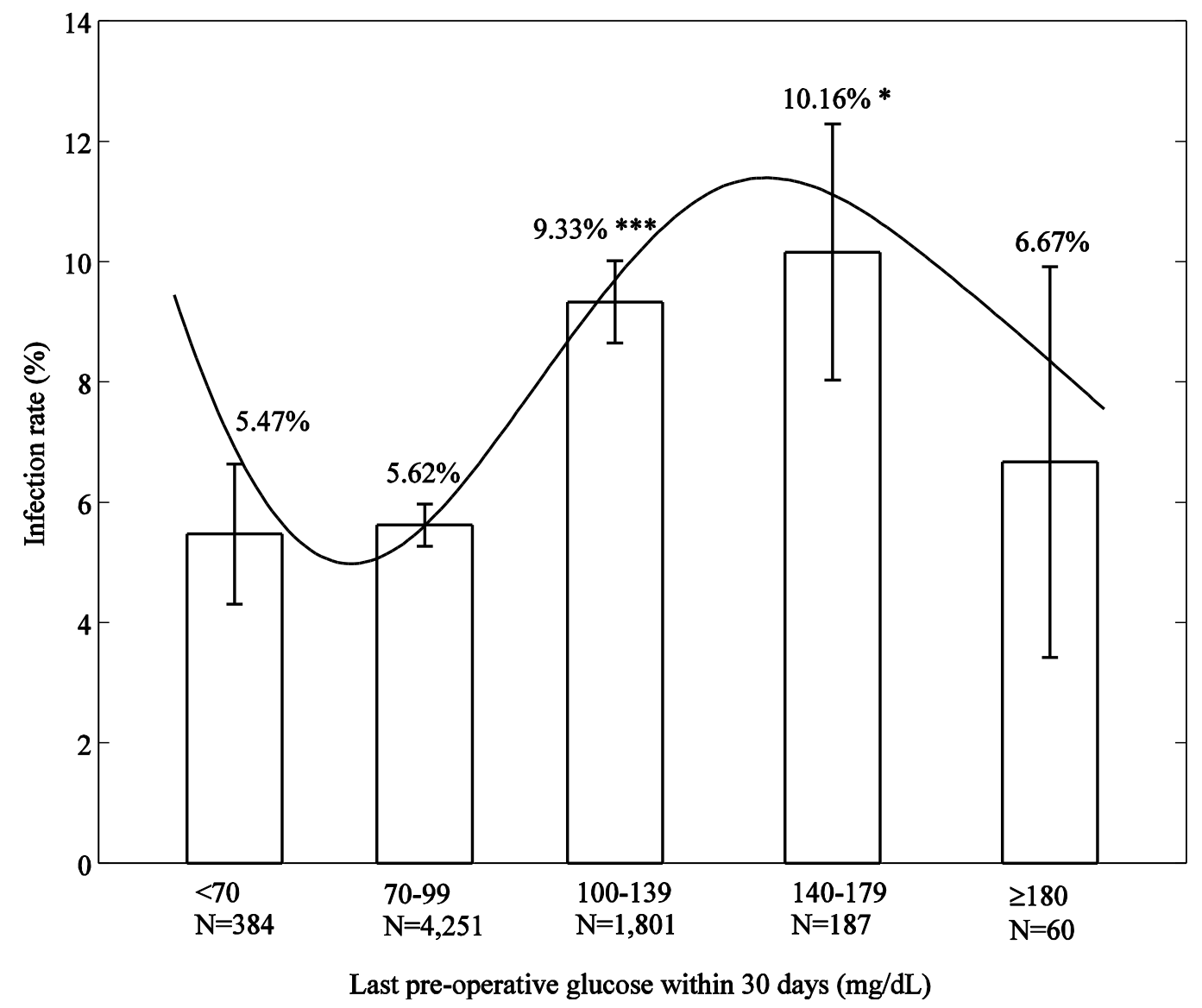

Figure 2 - Percent of patients without known diabetes with any post-operative infections grouped by clinically relevant cut-off points for last glucose levels measured within 30 days prior to surgery. Number of patients in each group is listed along with the percent infection rate. Overlying cubic spline model is shown. ${ }^{*}$ p-value $<0.05$ compared with pre-operative glucose 70-99 mg/dL; *** p-value $<0.001$ compared with pre-operative glucose 70-99 mg/dL. 


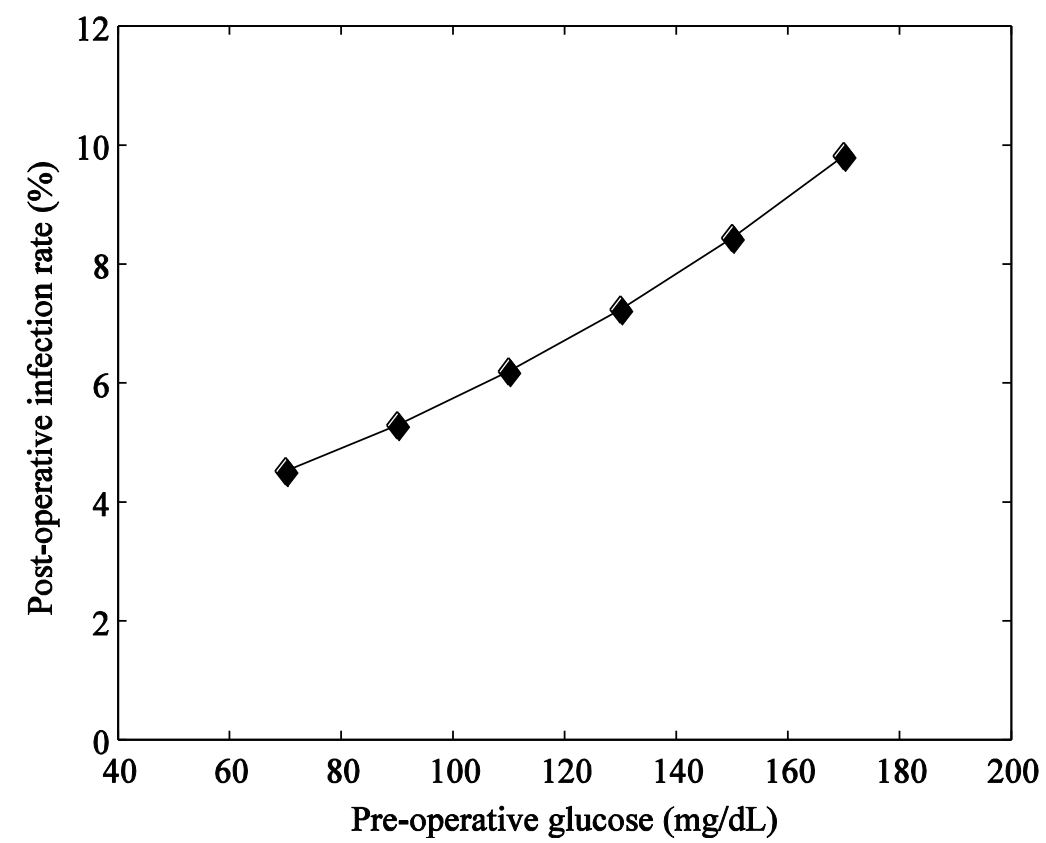

Figure 3 - Pre-operative glucose level as a marker for post-operative infection, over the range of 70-179 mg/dl, adjusted for age, gender, BMI, ASA classification, and type of surgery using multivariable logistic model. 